paraxanthine concentration. This is shown by the results of some experiments in which rats were given thyroxine until their basal metabolic rates reached 200 per cent of the normal, and were then given paraxanthine while the dosage with thyroxine was continued. If the dose of paraxanthine was appropriate (about $100 \mu \mathrm{gm}$. daily for this basal metabolic rate), the basal metabolic rate fell, sometimes nearly to the normal level. Similarly, excess paraxanthine may be neutralized by thyroxine. If a rat has a normal basal metabolic rate as a result of being given excess paraxanthine, an appropriate dose of thyroxine causes a fall of the basal metabolic rate; thyroxine has the opposite of its usual effect. This was an especially striking result, since an action of thyroxine opposite to that which occurs in all normal circum stances has never, so far as we know, been observed.

We think these results allow us to conclude that paraxanthine behaves as an antithyroid substance in the body under normal conditions, and that the control of the basal metabolic rate in the rat is by the presence or absence of certain 'balanced' proportions between the concentrations of paraxanthine and the thyroid secretion and not by the concentra. tion of either independently. If the concentrations are balanced, the basal metabolic rate is low ; excess of either substance raises the basal metabolic rate. We do not wish to suggest that in normal life changes in the paraxanthine content of the internal medium are used by the body to control the basal metabolic rate. We have no evidence at present whether the body has or has not any means of controlling the concentration of paraxanthine in the medium, as it has of controlling that of the thyroid secretion.

Work is being continued on these subjects, especially on the physiological activity of further purine derivatives akin to paraxanthine and on the distribution of paraxanthine in the body.

G. S. Carter.

Dept. of Zoology,

University of Cambridge.

G. N. JENkINS.

Dept. of Physiology,

St. Bartholomew's Medical College.

$$
\text { May } 20 .
$$

' Carter, G. S., Brit. J. Exp. Biol., 10, 256 (1933).

2 Berichte, 39, 423 (1906).

Berichte, 31, 2622 (1898).

'Z. Physiol. Chem., 24, 376 (1898).

'J. Physiol., 66, 299 (1928).

'J. Physiol., 68, 383 (1930).

\section{Liver Vacuoles and Anoxæmia}

DuRING an investigation, carried out on behalf of the Air Ministry in 1940, into the effects on animals of a sudden reduction in atmospheric pressure, one of our findings was the formation of large watery vacuoles in the cells of the liver. We have no access to the current German literature, and Dr. Ladewig's letter ${ }^{1}$ was our first intimation that somewhat similar findings had been published in 1942 by Büchner and his colleagues and also by Hesse. We think, therefore, that we should briefly report our findings and compare them with those of the German workers in so far as these are given in Dr. Ladewig's epitome.

The vacuoles which we found in the cytoplasm of liver cells were $2-12 \mu$ in diameter, most commonly about $7 \mu$. While some were perfectly spherical, many were slightly ovoid or polyhedral. The number in each cell varied from 1 to 12 and was most commonly 2-3. They were more commonly found adjacent to the nucleus than in the more peripheral cytoplasm. Some vacuoles were indented by the nucleus while others themselves indented the nucleus and distorted it to a crescentic shape. Their relative numbers varied a good deal in the different lobules, and in most, but not all, cases they were more numerous at the centre of the lobule. In paraffin and frozen sections they appeared as optically empty spaces containing neither fat nor glycogen. This description agrees with that given in Dr. Ladewig's epitome. We further showed that the vacuoles can be seen in living liver cells suspended in serum, and from their optical properties under these conditions we concluded that they were watery vacuoles, certainly neither gaseous nor lipoid.

The German workers found these vacuoles in airmen dying from the effects of high altitude, in animals exposed to an atmosphere of reduced oxygen content at normal pressure, and also in humans dying under conditions of acute anoxæmia (suffocation, drowning). They believed that in all cases the vacuoles were the result of anoxæmia.

In our experiments, vacuoles occurred in animals (rat, guinea pig, rabbit, monkey) which were explosively (that is, instantaneously) decompressed from a pressure of 1.0 to 0.016 atmosphere, in an atmosphere approximating to pure oxygen, the animals being kept at the low pressure for 2 hours before being sacrificed. A few of the animals died after 5-20 minutes exposure to the low pressure, and they, too, showed vacuoles. In these experiments we tried to prevent anoxæmia by passing oxygen through the chamber throughout the experiment, but we know from other evidence that the animals did suffer some degree of anoxæmia during their exposure to the low pressure. In these experiments, therefore, the vacuoles might have been due to anoxæmia, or to exposure to low pressure, or to the sudden reduction of pressure (decompression); though in the case of the animals dying after five minutes at low pressure the duration of the anoxæmia must have been very short.

We also found similar liver vacuoles in animals which were explosively decompressed from $6 \cdot 0$ to $1 \cdot 0$ atmospheres. In these experiments some of the animals died almost instantaneously as a result of the decompression, and vacuoles were found in them as well as in those which survived. In those animals which died instantaneously, both anoxæmia and exposure to low pressure seem to be excluded, and we reached the tentative conclusion that in all cases the vacuoles were the result of the sudden reduction of external pressure (decompression).

It seems likely, therefore, that these liver vacuoles can be produced by factors other than anoxæmia, and the contention that they afford a histological criterion for the occurrence of anoxæmia will require further investigation.

This work was part of a larger investigation carried out by I. de Burgh Daly, P. Eggleton, S. R. Elsden, C. O. Hebb and O. A. Trowell. As the histologist, I have in this instance acted as spokesman for the team.

Department of Physiology, O. A. TroweLL.

University of Edinburgh.

$$
\text { June } 1 \text {. }
$$

${ }^{1}$ Ladewig, P., NATURE, 151, 558 (1943). 